\title{
Clinicopathological values of NBS1 and DNA damage response genes in epithelial ovarian cancers
}

\author{
Yoo-Kyung Lee ${ }^{1,2,3}$, Noh-Hyun Park ${ }^{2}$ and Hyunsook Lee ${ }^{1}$
}

Epithelial ovarian cancers (EOCs) are highly lethal gynecological malignancies with a high recurrence rate. Therefore, developing prognostic markers for recurrence after chemotherapy is crucial for the treatment of ovarian cancers. As ovarian cancers frequently respond to DNA-damaging agents, we assessed the clinicopathological significance of key double-strand DNA break (DSB) repair genes, including BRCA1, BRCA2, BARD1, ATM, RAD51 and NBS1 in EOC cell lines and paraffin-embedded tissue sections from 140 EOC patients treated with cytoreductive surgery, followed by platinum-based chemotherapy. These samples were analyzed for the clinicopathological impact of DSB genes by western blot analysis, immunohistochemistry and quantitative real-time PCR. Of the DSB repair genes, BRCA1, ATM and NBS1, which are involved in the homologous recombinationmediated repair pathway, were related to aggressive parameters in EOC. When survival analysis was performed, NBS1 expression exhibited an association with EOC recurrence. Specifically, increased NBS1 expression was found in 107 out of 140 cases (76.0\%) and correlated with advanced stage $(P=0.001)$, high grade $(P=0.001)$ and serous histology $(P=0.008)$. The median recurrence-free survival in patients with positive and negative expression of NBS1 was 30 and 78 months, respectively $(P=0.0068)$. In multivariate analysis, NBS1 was an independent prognostic factor for the recurrence of EOC. Together, these results suggest that NBS1 is a marker of poor prognosis for the recurrence of EOC and is associated with aggressive clinicopathological parameters.

Experimental \& Molecular Medicine (2015) 47, e195; doi:10.1038/emm.2015.85; published online 20 November 2015

\section{INTRODUCTION}

Epithelial ovarian cancer (EOC) is the fifth most common cause of cancer mortality in women and the leading cause of mortality among gynecological cancers. ${ }^{1}$ Although cytoreductive surgery followed by adjuvant chemotherapy enhances clinical responses in the majority of ovarian cancer patients, many of them experience recurrence of the disease and eventually die from resistance to chemotherapy, especially to platinum-based chemotherapy. ${ }^{2}$ Mechanisms that underlie platinum resistance are poorly understood and are most likely multifactorial in origin. ${ }^{3,4}$

To date, poly ADP (adenosine diphosphate) ribose polymerase (PARP) inhibitor treatment is one of the most promising examples of personalized therapy for ovarian cancer. ${ }^{5}$ PARP inhibitor was originally developed during synthetic lethality screening of BRCA2 mutant cells. ${ }^{6}$ Both BRCA1 and BRCA2 are involved in homologous recombination (HR), which repairs double-strand DNA breaks (DSB) in an error-free manner. ${ }^{7}$ In cells with $B R C A 1$ or BRCA2 mutations, a compensatory mechanism of DNA repair, such as base excision repair is necessary to restore DNA damage in place of HR. PARP is an enzyme involved in base excision repair, and hence BRCA-null cells showed hypersensitivity to PARP inhibitors that targeted base excision repair in general. Therefore, PARP inhibitors may be effective in treatment of ovarian cancers with $B R C A$ mutations.

Approximately $10 \% \sim 15 \%$ of EOCs are associated with inherited BRCA1 or BRCA2 mutations. However, dysfunction of the BRCA-related HR pathway may be more prevalent. ${ }^{8}$ This phenomenon characterized by HR deficiency is called 'BRCAness. ${ }^{9}$. Therefore, these sporadic tumors with a BRCAness phenotype will behave similar to BRCA1 or BRCA2 mutant cancers and may show sensitivity to PARP inhibitors. ${ }^{10}$ Until now, BRCAness phenotypes, including the somatic mutation of BRCA1 or BRCA2 and the epigenetic hypermethylation of the BRCA1 promoter have been reported in EOC. ${ }^{11-15}$ However, development of prognostic markers for EOC, other than

\footnotetext{
${ }^{1}$ Department of Biological Sciences and Institute of Molecular Biology and Genetics, Seoul National University, Seoul, Korea; ${ }^{2}$ Department of Obstetrics and Gynecology, Seoul National University Hospital, Seoul, Korea and ${ }^{3}$ Department of Obstetrics and Gynecology, Cheil General Hospital, College of Medicine, Dankook University, Seoul, Korea

Correspondence: Professor H Lee, Department of Biological Sciences and Institute of Molecular Biology and Genetics, Seoul National University, 1 Gwanak-Ro, Gwanak-Gu, Seoul 151-742, Korea.

E-mail: HL212@snu.ac.kr
}

Received 27 August 2015; accepted 31 August 2015 
BRCA1 or BRCA2, for treatment with PARP inhibitors is needed for advanced patient-specific cancer therapy.

Here we asked whether mutations in HR pathway genes are associated with an improved response rate and survival after platinum-based chemotherapy. By assessing the mRNA and protein expression patterns of $\mathrm{HR}$ genes in EOC, we report that NBS1 is a marker of poor prognosis for EOC and has clinicopathological value.

\section{MATERIALS AND METHODS}

\section{Cell culture of ovarian cancer cell lines and primary ovarian} cancers

Human ovarian cancer cell lines OVCAR3, SK-OV-3, SNU8, SNU119 and SNU251 (BRCA1 mutated) were obtained from the Korean Cell Line Bank and grown in monolayer cultures in RPMI 1640 supplemented with fetal bovine serum (10\% v/v). The HCC1937 (BRCA1 mutated) breast cancer cell line and the CAPAN1 (BRCA2 mutated) pancreatic cell line were grown in RPMI 1640, and HeLa cells were grown in Dulbecco's modified Eagle's medium supplemented with fetal bovine serum $(10 \% \mathrm{v} / \mathrm{v})$.

Primary ovarian cancer samples were collected from the Seoul National University Hospital from patients undergoing cytoreductive surgery. Tumor tissue was dissected onto $100-\mathrm{mm}$ petri dishes containing serum-free RPMI medium supplemented with trypsin. After 30 min at $37^{\circ} \mathrm{C}$, cells were resuspended and maintained in RPMI 1640 supplemented with fetal bovine serum $(10 \% \mathrm{v} / \mathrm{v})$.

\section{Patients and tissue samples}

Tissue specimens for quantitative real-time PCR and immunohistochemistry (IHC) were obtained from 140 epithelial ovarian carcinomas by primary cytoreductive surgery, followed by platinum-based chemotherapy at Seoul National University Hospital between 1998 and 2005. All samples were taken from primary ovarian lesions in each patient. The disease stage of each sample was determined according to the International Federation of Gynecology and Obstetrics (FIGO) criteria. Of the patients, 78 experienced a relapse and 35 died of ovarian cancer. Samples of normal ovarian tissue were obtained from the unaffected ovaries of 10 ovarian cancer patients (stage I or II), whose tumor was limited to the contralateral ovary. Formalin-fixed, paraffin-embedded ovarian carcinoma tissues were used for histologic evaluation. Gynecological pathologists reviewed all hematoxylin and eosin-stained sections. The Seoul National University Hospital Institutional Review Board approved this study (1006-089-414).

\section{RNA preparation}

Three sets of 1.0- $\mu$ m-thick tissue from paraffin block were dewaxed with xylene, which was removed using three changes of absolute ethanol. Total RNA was extracted from tissue using a High Pure Paraffin RNA Kit (Roche Diagnostics, Indianapolis, IN, USA) according to the manufacturer's instructions. For assessment of total RNA concentration and purity, a NanoDrop ND-1000 (NanoDrop Technologies, Thermo Scientific, Wilmington, DE, USA) measured absorbance at $260 \mathrm{~nm}$.

\section{Quantitative real-time reverse-transcriptase PCR}

Total RNA was reverse transcribed in a final volume of $40 \mu \mathrm{l}$ containing oligo dTs and $1 \mu \mathrm{g}$ of total RNA and with a Superscript II RNase $\mathrm{H}$ reverse Transcriptase Kit (Invitrogen, Waltham, MA, USA). Quantitative real-time reverse-transcriptase PCR was performed with a sequence detector (StepOnePlus, Applied Biosystems, Foster City, CA, USA) based on the SYBR Premix Ex Taq assay (Takara, Otsu, Japan) according to the manufacturer's protocol. The following sequences were used as forward $(\mathrm{F})$ and reverse $(\mathrm{R})$ primers: BRCA1 F: 5'-GAGGAGTTCTT-GACCCCAA-3', BRCA1 R: 5'-CAGAATCAC CCGAGCAGGT-3'; BRCA2 F: 5'-CAGC-GTGGAAATATCCTAAAT CTGA-3', BRCA2 R: 5'-TTGGATGAACAGGAATACTTG-GAA-3'; BARD1 F: 5'-TCTGTAATGGTGTGCTTCAAGG-3', BARD1 R: 5'-GTGTCCAGC-ATCCAGAAAGG-3'; RAD51 F: 5'-CCCTGCAGC CAGGCACT-3', RAD51 R: 5'-AG-GCCAACTGCGCGGAT-3'; NBS1 F: 5'-GGTGGGAAGGACCTGATGATAG-3'，NBS1 R: 5'-GGGCG AGGCTCATCGAT-3'; and glyceraldehyde-3-phosphate dehydrogenase F: 5'-TGGTCACCAGGGCTGCTTTTA-3', glyceraldehyde-3phosphate dehydrogenase R: 5'-TCCTGGAAGATGGTGATGGGA TTT- $3^{\prime}$. Cycling conditions used in this PCR series were $95^{\circ} \mathrm{C}$ for $10 \mathrm{~min}$ to activate DNA polymerase, followed by 40 cycles at $95^{\circ} \mathrm{C}$ for $15 \mathrm{~s}, 55^{\circ} \mathrm{C}$ for $20 \mathrm{~s}$ and $72^{\circ} \mathrm{C}$ for $10 \mathrm{~s}$.

All specimens were analyzed in duplicate and the mean values were used for quantification. The quantification value of $B R C A 1, B R C A 2$, BARD1, RAD51, ATM or NBS1 mRNA was described relative to GAPDH mRNA. To exclude false positives, we used the mean relative mRNA value plus 2 s.d. of expressed mRNA in EOC as the cutoff value to detect expression of a corresponding gene. In this manner, values above the cutoff were defined as positive expression for the corresponding mRNA.

\section{Western blot analysis}

Protein concentrations were measured by Bradford protein assay before analysis. Total cell lysate (30-150 $\mu$ g of protein) was separated by $8 \%$ or $12 \%$ polyacrylamide SDS-polyacrylamide gel electrophoresis and transferred to a nitrocellulose membrane. After blocking nonspecific binding sites for $1 \mathrm{~h}$ with $5 \%$ non-fat milk in TBS-T (Trisbuffered saline, $0.1 \%$ Tween 20 ), the membrane was incubated at $4{ }^{\circ} \mathrm{C}$ overnight with primary antibodies against BRCA1 antibody (Oncogene, La Jolla, CA, USA), BRCA2 (Calbiochem, La Jolla, CA, USA), NBS1 (Santa Cruz Biotechnology, Dallas, TX, USA) and $\beta$-actin (Santa Cruz Biotechnology). The blot was washed three times with TBS-T and incubated with horseradish peroxidase-conjugated goat antimouse secondary antibody at room temperature for $1 \mathrm{~h}$.

\section{IHC analysis}

Paraffin blocks from ovarian carcinoma were sectioned at $4 \mu \mathrm{m}$ adjacent to hematoxylin and eosin-stained sections. Samples were deparaffinized in xylene, rehydrated with graded ethanol and washed in distilled water. The sections were then placed in $10 \mathrm{~mm}$ citrate buffer ( $\mathrm{pH}$ 6.0) and boiled in a microwave for epitope retrieval. Endogenous peroxidase activity was quenched by incubating tissue sections in $3 \% \mathrm{H}_{2} \mathrm{O}_{2}$ for $10 \mathrm{~min}$. Following the blocking procedure with $20 \%$ goat serum and $1 \%$ bovine serum albumin in phosphatebuffered saline at room temperature for $1 \mathrm{~h}$, sections were incubated with primary antibody against NBS1 at a dilution of 1:100 in a humidifying chamber at $4{ }^{\circ} \mathrm{C}$ overnight. Next the sections were washed in phosphate-buffered saline for $5 \mathrm{~min}$ at room temperature and subsequently stained by the labeled streptavidin biotin method as suggested by the manufacturer of the Dako LSAB Kit (Dako, Agilent Technologies, Glostrup, Denmark), and were visualized using 3,3'diaminobenzidine. The sections were then counterstained with hematoxylin. Slides were subjected to the same staining procedure without addition of primary antibodies as a negative control. Microscopy fields from each stained section were randomly sampled. 
In the majority of cases, NBS1 antibody staining was nuclear. However, a few specimens showed cytoplasmic staining. The distribution of the percentage of positive staining was recorded and scored as previously reported. ${ }^{16}$ Briefly, a score of 0 indicated no appreciable staining in cells, 1 indicated appreciable nuclear staining without cytoplasmic staining or with cytoplasmic staining in $<25 \%$ of cells and 2 indicated significant nuclear staining and $>25 \%$ of cells with cytoplasmic staining.

\section{Statistical analysis}

The relationships between categorical variables were assessed using the $\chi^{2}$-test. The Student's $t$-test was used to compare relative mRNA expression levels between groups. Recurrence-free survival (RFS) was estimated using the Kaplan-Meier method and the differences in survival were compared using the log-rank test. Multivariate analysis was performed using the Cox regression method. A $P$-value of $<0.05$ was considered statistically significant. Data were analyzed using SPSS software, version 15.0 (SPSS Inc., Chicago, IL, USA).

\section{RESULTS}

BRCAness gene expression levels in EOC cells

Western blot analysis was performed to assess the expression profiles of the genes involved in the DSB repair pathway, including BRCA1, BRCA2, BARD1, RAD51, NBS1 and ATM in OVCAR3, SK-OV-3, SNU8, SNU119 and SNU251 ovarian cancer cells. The HCC1937, BRCA1-deficient breast cancer cell line, the CAPAN1, BRCA2-deficient cell line, and HeLa cells, which is positive for both BRCA1 and BRCA2, were used as controls. As expected, HCC1937 cells were negative for BRCA1 and CAPAN1 cells were negative for BRCA2. One of the ovarian cancer cell lines investigated, SNU-251, did not express BRCA1. Notably, mRNA levels of NBS1, BARD1, ATM, $R A D 51, B R C A 1$ and $B R C A 2$ were variable among the cell lines tested (Figure 1a).

Western blot analysis showed that, similar to the mRNA results, the SKOV3 and SNU119 cells, in addition to the SNU251 and HCC1937 cells, did not have BRCA1 protein. Interestingly, SNU119 cells were negative for both BRCA1 and BRCA2. In conclusion, mRNA and protein levels of NBS1, BRCA1, BRCA2 and RAD51 in ovarian cancer cell lines were variable (Figure $1 \mathrm{~b}$ ).

\section{BRCAness gene expression levels in EOC patients}

Next, we assessed the mRNA levels of BRCA1, BRCA2, RAD51 and NBS1 in 140 ovarian cancer patient samples. When compared with those in normal ovary tissue, all six mRNA levels were altered (Table 1 and Figure 2). The mRNA level of NBS1 exhibited a significant difference between normal and cancer lesions in EOC patient samples (Figure 2a). In simultaneous semi-quantitative reverse-transcriptase PCR analysis, BRCA1 and ATM expression levels displayed a statistically significant difference between normal and tumor samples, in addition to expression of NBS1 (Figure 2b and Table 1). Interestingly, BRCA1 and NBS1 were overexpressed in tumors, whereas ATM expression was reduced (Table 1).

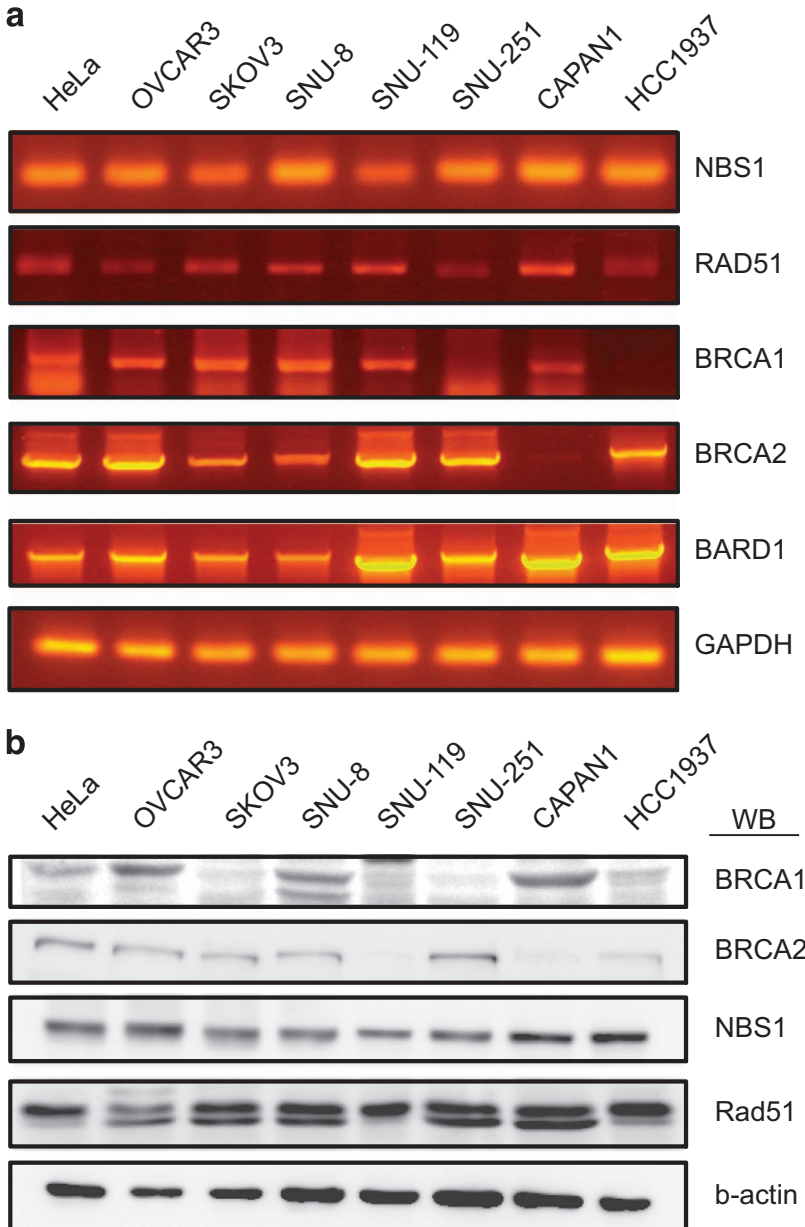

Figure 1 (a) mRNA expression profiles of BRCA1, BRCA2, BARD1, $A T M, N B S 1$ and RAD51 in EOC cell lines. BRCA1 and BRCA2 mutated cancer cell lines HCC1937 and CAPAN1, respectively, were used for controls. GAPDH was used as a loading control. (b) Western blot analysis in EOC cell lines, and BRCA1 and BRCA2 mutated cancer cell lines. Anti- $\beta$-actin was used as a loading control.

Table $1 \mathrm{mRNA}$ levels of DNA damage response genes in ovarian tissue samples

\begin{tabular}{lcc}
\hline Gene & $\begin{array}{c}\text { Median mRNA level (range) } \\
\text { of normal ovary }(\mathrm{n}=10)\end{array}$ & $\begin{array}{c}\text { Median mRNA level (range) of } \\
\text { ovarian cancer }(\mathrm{n}=140)\end{array}$ \\
\hline BRCA1 & $1(0.71-2.11)$ & $2.26(0.08-8.25)$ \\
BRCA2 & $1(0.57-1.62)$ & $1.95(0.16-10.12)$ \\
BARD1 & $1(0.51-1.56)$ & $0.51(0.01-1.30)$ \\
RAD51 & $1(0.35-3.21)$ & $2.03(0.60-5.87)$ \\
NBS1 & $1(0.18-1.98)$ & $3.32(0.32-28.22)$ \\
ATM & $1(0.85-1.62)$ & $0.76(0.22-1.98)$ \\
\hline
\end{tabular}

Correlation between NBS1 levels and patient survival Next, IHC staining was performed on 140 paraffin-embedded tumor samples (Table 2). The age of cancer patients ranged from 18 to 79 years (median, 51.5 years). All of the cancer patients analyzed were at stage Ic or higher, and hence 
a

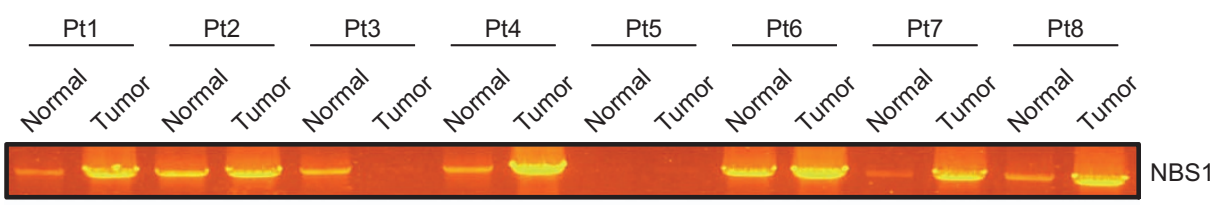

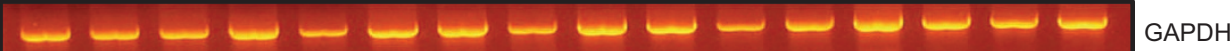

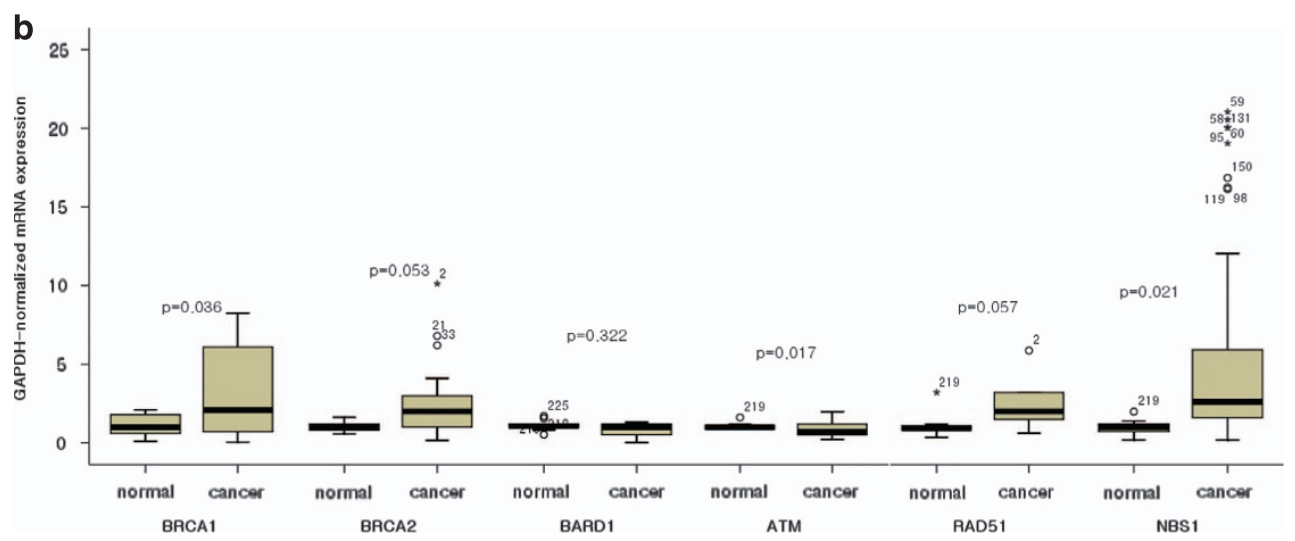

Figure 2 (a) NBS1 mRNA expression profiles in EOC patient samples. NBS1 mRNA expression of eight representative pairs of EOC cases was analyzed by reverse-transcriptase PCR. GAPDH was included for normalization. Tumor (Tumor) and non-cancerous matched tissues (Normal) were compared in all cases. (b) The mRNA expression patterns of indicated genes in 140 EOC patient samples compared with that in normal ovary (mean \pm s.e.m.). All $P$-values were obtained by Student's $t$-test between groups.

Table 2 Clinicopathological characteristics of ovarian cancer patients

\begin{tabular}{lc}
\hline & Number of patients (\%) \\
\hline Median age (year, range) & $51.5(18-79)$ \\
FIGO stage & \\
IC & $23(16.4)$ \\
II & $13(9.3)$ \\
III & $86(61.4)$ \\
IV & $18(12.9)$ \\
Histology & \\
Serous & \\
Mucinous & $82(58.6)$ \\
Endometrioid & $21(15.0)$ \\
Clear cell & $20(14.3)$ \\
Others & $15(10.7)$ \\
Grade & $2(1.4)$ \\
1 & \\
2 & $23(16.4)$ \\
3 & $38(27.1)$ \\
Residual tumor & $79(56.4)$ \\
Residual tumor $\leqslant 1 \mathrm{~cm}$ & \\
Residual tumor $>1 \mathrm{~cm}$ & $73(52.1)$ \\
Clinical response & $67(47.9)$ \\
Complete response & \\
Partial response & \\
Stable disease & \\
Progressive disease & $91(65.0)$ \\
\hline
\end{tabular}

underwent primary cytoreductive surgery, followed by taxane and platinum chemotherapy. None of the patients underwent conservative surgery. Serous cystadenocarcinoma $(57.5 \%)$ was the most common histology. Cytoreductive surgery was optimal ( $\leqslant 1 \mathrm{~cm}$ residual disease) in $51.9 \%$ of cases. More than two-thirds of the patients had a complete response to the firstline treatment, yet half of them relapsed.

NBS1 expression levels were associated with RFS in the EOC patients treated with cytoreductive surgery followed by platinum-based chemotherapy, whereas BRCA1, BRCA2, $B A R D 1, A T M$ and RAD51 mRNA levels were not. Relative NBS1 mRNA expression was correlated with IHC staining score, which reflects the protein expression level (Figure 3a). An analysis of the relationship between the levels of NBS1 and the clinicopathological parameters of 140 tumors was analyzed (Table 3) and showed that positive NBS1 expression was associated with advanced stage $(P=0.001)$, serous histology $(P=0.008)$, high grade $(P=0.001)$ and residual tumor $(P=0.021)$.

Univariate survival analysis showed that NBS1 immunoreactivity was a significant prognostic factor for RFS $(P<0.001)$, whereas BRCA1, BRCA2 and RAD51 expression was not $(P=0.059, P=0.633$ and $P=0.222$, respectively). Patients immunoreactive for NBS1 (score 2) had a median RFS of 30 months (range, 3-48 months), whereas those lacking NBS1 expression (score 0 and 1) had a median RFS of 78 months (range, 2-115 months; Figure 3b). Multivariate survival analysis indicated that the NBS1 level was an independent prognostic factor for predicting recurrence of ovarian cancer (Table 4). RFS curves stratified by NBS1 mRNA expression and NBS1 protein expression corroborated that NBS1 has prognostic value for RFS in EOC (Figure $4 \mathrm{a}$ and $\mathrm{b}$ ). 
a
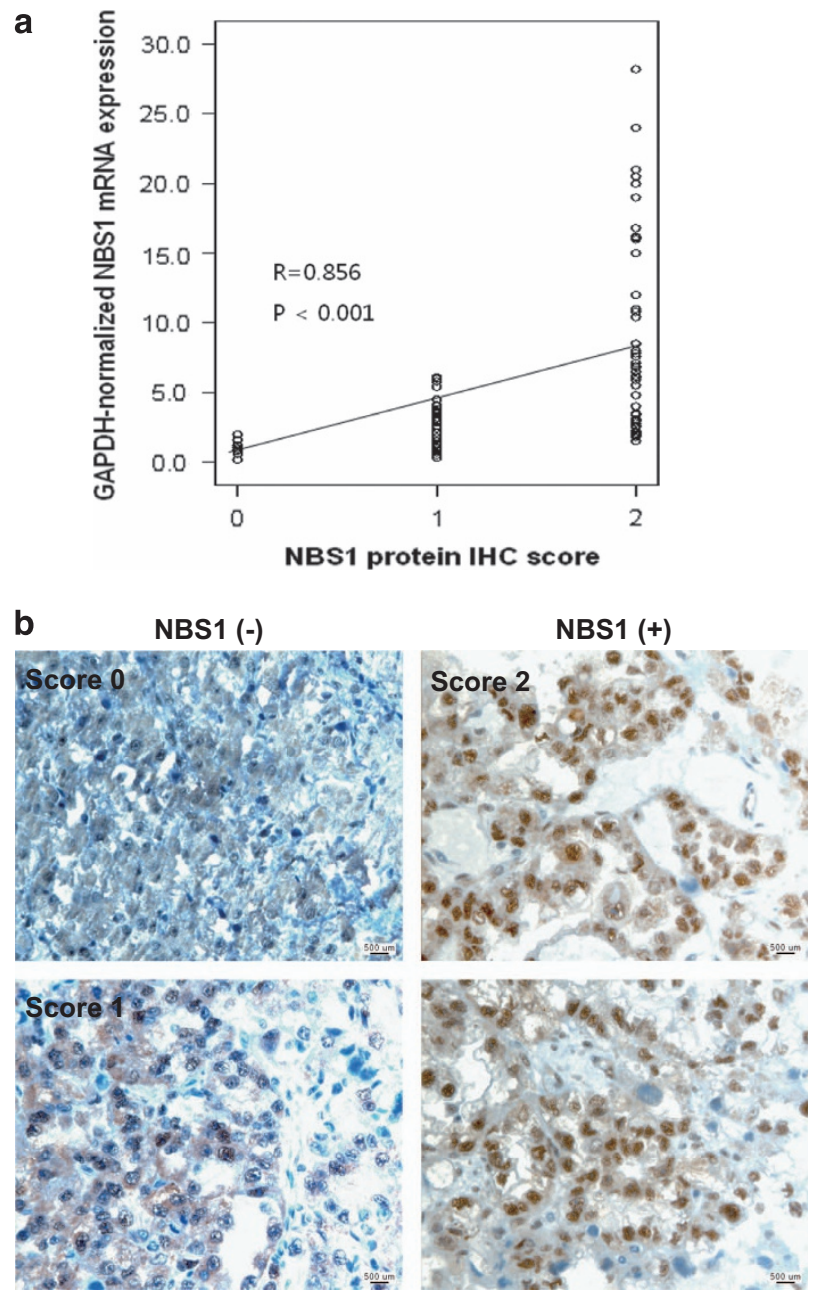

Figure 3 Correlation between NBS1 mRNA expression and immunohistochemical (IHC) scoring of NBS1 in primary EOC tissues. (a) Relative NBS1 mRNA expression levels of 140 EOC patient samples estimated using real-time reverse-transcriptase PCR (RT-PCR) analysis were correlated with IHC scores 0,1 and 2. GAPDH was used as an internal control for real-time RT-PCR analysis. (b) Representative positive and negative immunohistochemistry images of NBS1 in paraffin-embedded EOC samples. Images were taken on an Olympus BX-51 microscope under $\times 100$ magnification. Scale bar, $500 \mu \mathrm{m}$.

\section{DISCUSSION}

In this study, we asked whether the genes involved in HR affect cancer aggressiveness and EOC prognosis in patients after platinum-based chemotherapy. We found that NBS1 expression was heterogeneous in different EOCs and an increased NBS1 level was a significant marker of poor prognosis in EOC patients treated with cytoreductive surgery followed by platinum-based chemotherapy.

Anti-neoplastic activity of platinum results from its DNA cross-linking activity. Normal cells cope with the DNA crosslinks through specific DNA repair pathways that include the BRCA pathway, ${ }^{7,17}$ whereas cancer cells with defects in the DNA damage response are more sensitive to platinum and die. Indeed, the results shown here suggest that alteration in NBS1
Table 3 Correlation of NBS1 protein level and clinicopathological parameters

\begin{tabular}{|c|c|c|c|c|}
\hline & \multirow{2}{*}{$\begin{array}{c}\text { Number of } \\
\text { patients }\end{array}$} & \multicolumn{2}{|c|}{ NBS1 expression } & \multirow[b]{2}{*}{ P-value } \\
\hline & & Negative & Positive & \\
\hline \multicolumn{5}{|l|}{ FIGO stage } \\
\hline Early (I, II) & 36 & 16 & 20 & 0.001 \\
\hline Advanced (III, IV) & 104 & 13 & 91 & \\
\hline \multicolumn{5}{|l|}{ Histology } \\
\hline Serous & 82 & 11 & 71 & 0.008 \\
\hline Non-serous & 58 & 22 & 36 & \\
\hline \multicolumn{5}{|l|}{ Grade } \\
\hline 1 & 23 & 14 & 9 & 0.001 \\
\hline 2 and 3 & 117 & 16 & 101 & \\
\hline \multicolumn{5}{|l|}{ Residual tumor } \\
\hline$\leqslant 1 \mathrm{~cm}$ & 73 & 28 & 45 & 0.021 \\
\hline$>1 \mathrm{~cm}$ & 67 & 5 & 62 & \\
\hline
\end{tabular}

Table 4 Univariate and multivariate analysis of prognostic factors in ovarian cancer patients for RFS

\begin{tabular}{|c|c|c|c|}
\hline & \multirow{2}{*}{$\begin{array}{c}\text { Univariate } \\
\text { analysis } \\
\text { P-value }\end{array}$} & \multicolumn{2}{|c|}{ Multivariate analysis } \\
\hline & & P-value & $R R(95 \% \mathrm{Cl})$ \\
\hline \multicolumn{4}{|l|}{ FIGO stage } \\
\hline $\begin{array}{l}\text { Early (I, II) vs advanced } \\
\text { (III, IV) }\end{array}$ & $<0.001$ & 0.001 & 4.375 (2.920-6.555) \\
\hline \multicolumn{4}{|l|}{ Histology } \\
\hline Serous vs non-serous & $<0.001$ & 0.045 & $0.363(0.240-0.549)$ \\
\hline \multicolumn{4}{|l|}{ Grade } \\
\hline 1 vs 2 and 3 & 0.004 & 0.012 & $2.269(1.686-3.053)$ \\
\hline \multicolumn{4}{|l|}{ Residual tumor } \\
\hline$\leqslant 1 \mathrm{~cm} \mathrm{vs}>1 \mathrm{~cm}$ & $<0.001$ & 0.006 & $3.197(1.905-5.364)$ \\
\hline \multicolumn{4}{|l|}{ NBS1 expression } \\
\hline Negative vs positive & 0.005 & 0.035 & 1.929 (1.400-2.656) \\
\hline
\end{tabular}

Abbreviations: $\mathrm{Cl}$, confidence interval; RFS, recurrence-free survival; $\mathrm{RR}$, relative risk.

expression level is associated with BRCAness, similar to $B R C A 1$ and BRCA2 in BRCA1- or BRCA2 mutated cancers. As EOCs that are sensitive to platinum are likely to have alterations in BRCA or the Fanconi Anemia pathway, ${ }^{18,19}$ the results shown here suggest that alteration in NBS1 might reflect BRCAness, and that the BRCAness may be more prevalent in EOC than originally assumed, despite the small number of BRCA carriers in EOCs $(10 \%-15 \%)$. 

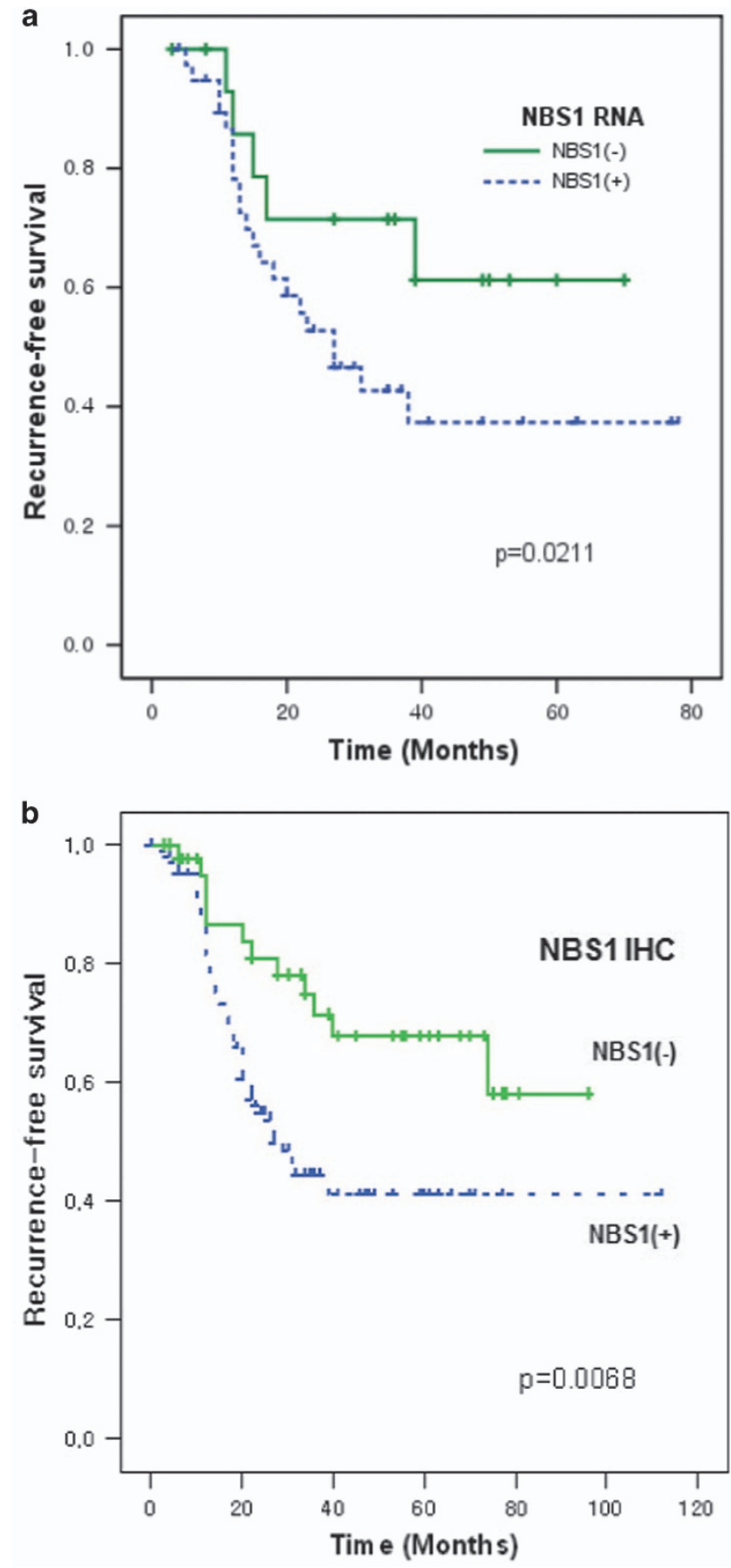

Figure 4 Recurrence-free survival (RFS) using the Kaplan-Meier method in relation to NBS1 levels. (a) Increased NBS1 mRNA expression in the tumor shows poor RFS $(P=0.0211)$. (b) NBS1 immunostaining score shows a significant correlation with RFS $(P=0.0068)$.

To evaluate the impact of BRCAness genes related to HR in EOC, we selected representative BRCAness genes, including BRCA1, BRCA2, BARD1, ATM, NBS1 and RAD51. Among them, the current study identified a novel association between NBS1 and EOC recurrence after treatment with cytoreductive surgery followed by platinum-based chemotherapy.
DSBs are repaired by non-homologous end-joining or HR. NBS1 is a critical component of the MRN complex (MRE11RAD50-NBS1), which senses DSBs and has an essential role in processing DSBs before non-homologous end-joining or $\mathrm{HR}^{20,21}$ Inheritance of NBS1 mutation is the cause of the recessive genetic disorder Nijmegen breakage syndrome, manifested by elevated sensitivity to irradiation, chromosome instability and cancer predisposition. ${ }^{22}$ A high level of NBS1 expression is a prognostic marker in advanced head and neck squamous cell carcinoma and squamous cell carcinoma of the oral cavity. ${ }^{16,23}$ In lung cancer, a single-nucleotide polymorphism in NBS1 has been reported to modulate the occurrence of TP53 mutations and contribute to carcinogenesis. ${ }^{24}$ In this study, we showed that NBS1 expression has prognostic relevance in EOC, and that elevated levels of NBS1 are associated with an advanced stage and grade of ovarian cancer.

Immunostaining of NBS1 protein by standard IHC techniques showed a strong association with tumor severity and metastatic death, strongly suggesting that IHC for NBS1 may be a clinically useful prognostic tool that can be applied at the time of initial surgical treatment. Mutations of the NBS1 gene lead to multiple cancers including breast ${ }^{25}$ EOC, ${ }^{26}$ bladder, ${ }^{27}$ nasopharyngeal cancer ${ }^{28}$ and leukemia. ${ }^{29}$ Cancer polymorphism in NBS1 may be a genetic modifier for the occurrence and aggression of cancer.

In conclusion, we suggest that NBS1 is a reliable prognostic marker for predicting RFS after initial treatment, and that assessing the levels of NBS1 can influence decisions in the adequate treatment of EOC. Furthermore, modulating the DNA repair pathway activity with PARP inhibitors may be a promising future approach to tailored therapy of EOC.

\section{CONFLICT OF INTEREST}

The authors declare no conflict of interest.

\section{ACKNOWLEDGEMENTS}

All experiments were approved by the Seoul National University Hospital IRB (1006-089-414). This study was supported by the Drug development program by NRF (2012 M3A9A 8052645), the Cancer Control program by the Korean Ministry of Health and Welfare (1220210) and the National Research Lab Program by NRF to HL (2013R1A2A1A01009184).

1 Siegel R, Ma J, Zou Z, Jemal A. Cancer statistics, 2014. CA Cancer J Clin 2014; 64: 9-29.

2 Kristensen GB, Trope C. Epithelial ovarian carcinoma. Lancet 1997; 349 113-117.

3 Stordal B, Davey R. A systematic review of genes involved in the inverse resistance relationship between cisplatin and paclitaxel chemotherapy: role of BRCA1. Curr Cancer Drug Targets 2009; 9: 354-365.

4 Vasey PA. Resistance to chemotherapy in advanced ovarian cancer: mechanisms and current strategies. Br J Cancer 2003; 89(Suppl 3): S23-S28.

5 Fong PC, Yap TA, Boss DS, Carden CP, Mergui-Roelvink M, Gourley C et al. Poly(ADP)-ribose polymerase inhibition: frequent durable responses in BRCA carrier ovarian cancer correlating with platinum-free interval. J Clin Oncol 2010; 28: 2512-2519. 
6 Tutt AN, Lord CJ, McCabe N, Farmer H, Turner N, Martin NM et al. Exploiting the DNA repair defect in BRCA mutant cells in the design of new therapeutic strategies for cancer. Cold Spring Harb Symp Quant Biol 2005; 70: 139-148.

7 D'Andrea AD, Grompe M. The Fanconi anaemia/BRCA pathway. Nat Rev Cancer 2003; 3: 23-34.

8 Mukhopadhyay A, Elattar A, Cerbinskaite A, Wilkinson SJ, Drew Y, Kyle $\mathrm{S}$ et al. Development of a functional assay for homologous recombination status in primary cultures of epithelial ovarian tumor and correlation with sensitivity to poly(ADP-ribose) polymerase inhibitors. Clin Cancer Res 2010; 16: 2344-2351.

9 Turner N, Tutt A, Ashworth A. Hallmarks of 'BRCAness' in sporadic cancers. Nat Rev Cancer 2004; 4: 814-819.

10 Drew Y, Mulligan EA, Vong WT, Thomas HD, Kahn S, Kyle S et al. Therapeutic potential of poly(ADP-ribose) polymerase inhibitor AG014699 in human cancers with mutated or methylated BRCA1 or BRCA2. J Nat/ Cancer Inst 2011; 103: 334-346.

11 Baldwin RL, Nemeth E, Tran H, Shvartsman H, Cass I, Narod S et al. BRCA1 promoter region hypermethylation in ovarian carcinoma: a population-based study. Cancer Res 2000; 60: 5329-5333.

12 Foster KA, Harrington P, Kerr J, Russell P, DiCioccio RA. Scott IV et al. Somatic and germline mutations of the BRCA2 gene in sporadic ovarian cancer. Cancer Res 1996; 56: 3622-3625.

13 Geisler JP, Hatterman-Zogg MA, Rathe JA, Buller RE. Frequency of BRCA1 dysfunction in ovarian cancer. J Natl Cancer Inst 2002; 94: 61-67.

14 Hilton JL, Geisler JP, Rathe JA, Hattermann-Zogg MA, DeYoung B, Buller RE. Inactivation of BRCA1 and BRCA2 in ovarian cancer. J Natl Cancer Inst 2002; 94: 1396-1406.

15 Teodoridis JM, Hall J, Marsh S, Kannall HD, Smyth C, Curto J et al. CpG island methylation of DNA damage response genes in advanced ovarian cancer. Cancer Res 2005; 65: 8961-8967.

16 Hsu DS, Chang SY, Liu CJ, Tzeng CH, Wu KJ, Kao JY et al. Identification of increased NBS1 expression as a prognostic marker of squamous cell carcinoma of the oral cavity. Cancer Sci 2010; 101: 1029-1037.

17 Lee H. Cycling with BRCA2 from DNA repair to mitosis. Exp Cell Res 2014; 329: 78-84.

18 D'Andrea AD. The Fanconi Anemia/BRCA signaling pathway: disruption in cisplatin-sensitive ovarian cancers. Cell Cycle 2003; 2: 290-292.

$19 \mathrm{Kim} \mathrm{H}$, D'Andrea AD. Regulation of DNA cross-link repair by the Fanconi anemia/BRCA pathway. Genes Dev 2012; 26: 1393-1408.

20 Lee JH, Paull TT. Direct activation of the ATM protein kinase by the Mre 11 Rad50/Nbs1 complex. Science 2004; 304: 93-96.
21 Paull TT. Mechanisms of ATM Activation. Annu Rev Biochem 2015; 84: 711-738.

22 Demuth I, Digweed M. The clinical manifestation of a defective response to DNA double-strand breaks as exemplified by Nijmegen breakage syndrome. Oncogene 2007; 26: 7792-7798.

23 Yang MH, Chiang WC, Chou TY, Chang SY, Chen PM, Teng SC et al. Increased NBS1 expression is a marker of aggressive head and neck cancer and overexpression of NBS1 contributes to transformation. Clin Cancer Res 2006; 12: 507-515.

24 Cho S, Kim MJ, Choi YY, Yoo SS, Lee WK, Lee EJ et al. Associations between polymorphisms in DNA repair genes and TP53 mutations in nonsmall cell lung cancer. Lung Cancer 2011; 73: 25-31.

25 Lu J, Wei Q, Bondy ML, Li D, Brewster A, Shete S et al. Polymorphisms and haplotypes of the NBS1 gene are associated with risk of sporadic breast cancer in non-Hispanic white women $<$ or $=55$ years. Carcinogenesis 2006; 27: 2209-2216.

26 Auranen A, Song H, Waterfall C, Dicioccio RA, Kuschel B, Kjaer SK et al. Polymorphisms in DNA repair genes and epithelial ovarian cancer risk. Int J Cancer 2005; 117: 611-618.

27 Broberg K, Bjork J, Paulsson K, Hoglund M, Albin M. Constitutional short telomeres are strong genetic susceptibility markers for bladder cancer. Carcinogenesis 2005; 26: 1263-1271.

28 Zheng J, Zhang C, Jiang L, You Y, Liu Y, Lu J et al. Functional NBS1 polymorphism is associated with occurrence and advanced disease status of nasopharyngeal carcinoma. Mol Carcinog 2011; 50: 689-696.

29 Jiang L, Liang J, Jiang M, Yu X, Zheng J, Liu H et al. Functional polymorphisms in the NBS1 gene and acute lymphoblastic leukemia susceptibility in a Chinese population. Eur J Haematol 2011; 86: 199-205.

(c) (1) (5) (2) This work is licensed under a Creative Commons Attribution-NonCommercial-ShareAlike 4.0 International License. The images or other third party material in this article are included in the article's Creative Commons license, unless indicated otherwise in the credit line; if the material is not included under the Creative Commons license, users will need to obtain permission from the license holder to reproduce the material. To view a copy of this license, visit http:// creativecommons.org/licenses/by-nc-sa/4.0/ 